\title{
Emphysematous Cystitis Responsible for a Bladder Perforation
}

\author{
M. Rachid, M. Graiouid, M. Dakir, A. Debbagh, and R. Aboutaieb
}

\begin{abstract}
Emphysematous cystitis is a rare form of lower urinary tract infection characterized by the presence of gas in the lumen and / or bladder wall. We report a case of a 64 year old patient hospitalized for an acute abdominal table. The diagnosis of emphysematous cystitis complicated by bladder perforation was made after performing an abdominal scan. Medico-surgical treatment has been initiated.
\end{abstract}

Index Terms- Emphysematous cystitis, bladder perforation.

\section{INTRODUCTION}

Emphysematous cystitis is a rare condition encountered mainly in unbalanced diabetic patients, immunocompromised or with a urinary tract obstacle. It represents a complication of infectious origin secondary to a microbial proliferation. The bacteria most often found are Escherichia coli and more rarely anaerobic bacteria [1] Diagnosis and rapid treatment conditions the prognosis which can be severe.

\section{OBSERVATION}

64-year-old patient with type 2 diabetes on metformin presents to the emergency room for acute abdominal pain associated with vomiting in a febrile context. The clinical examination revealed a fever at $39.5^{\circ}$, a tachycardia, hypotension, as well as a generalized abdominal defense. Biologically, an inflammatory syndrome was noted (leukocytes: 22,000 / mm3, CRP: $189 \mathrm{mg} / \mathrm{L}$ ). On the radiological assessment, the abdominal scanner showed the presence of gas in the pelvic cavity and in the bladder which was perforated (Figure 1). The patient was put on triantibiotic therapy and surgical exploration showed an appearance of bladder gangrene with large perforation of the dome and extensive inflammation of the digestive loops (Figure 2). A necrosectomy with bladder repair was performed with drainage by bladder catheter (Figure 3 ).

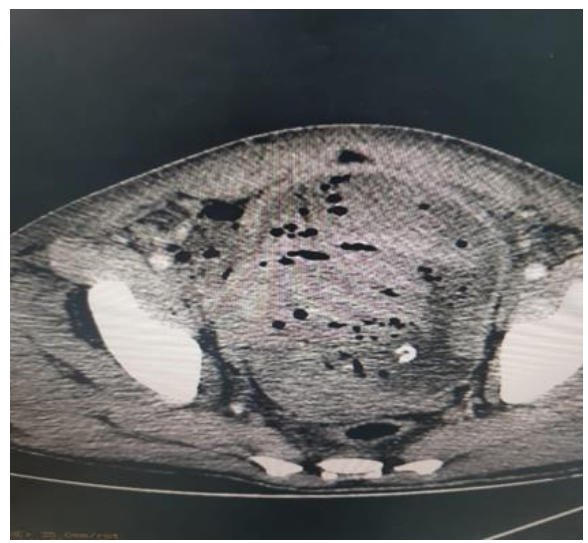

Fig. 1. Abdominal scanner showed the presence of gas in the pelvic cavity and in the bladder.

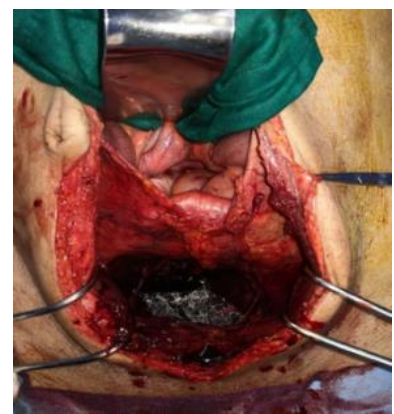

Fig. 2. Bladder gangrene with large perforation of the dome

\section{DISCUSSION}

Emphysematous cystitis is a rare condition complicating urinary tract infections, which most often affects diabetic women with a history of urinary incontinence and / or urinary retention. The other risk factors identified are immunosuppression, obstacles to the urinary tract and conditions promoting urinary stasis (neurological bladder, prostate adenoma). The average age is sixty-six [2]. The most common pathogens are E. coli and Klebsiella pneumonia [3]. Its evolution towards a bladder rupture is exceptional even in the absence of bladder drainage. The clinic for emphysematous cystitis is nonspecific with pain in $80 \%$ of cases, and irritant bladder signs in $50 \%$ of cases. It is asymptomatic in $7 \%$ of cases [4]. It should be discussed before any urinary tract infection in a patient at risk, especially in cases of hemodynamic instability. The abdominopelvic scanner is the reference imagery. Indeed, it makes it possible to establish a positive diagnosis, to carry out the assessment of extension of the gas collections and to search for a possible associated renal damage [5]. It also eliminates differential diagnoses: primary pneumaturia and communication with hollow organs such as bladder-vagina fistulas. Treatment for uncomplicated emphysematous 
cystitis is medical. It combines broad spectrum parenteral antibiotic therapy, the placement of an urinary catheter and strict glycemic control. The bladder rupture was secondary to emphysematous cystitis and urinary retention. Clinical signs of peritoneal irritation (contracture and / or abdominal defense) in a context of drained emphysematous cystitis must lead to the diagnosis of bladder perforation and to an emergency laparotomy. Hyperbaric oxygen therapy is not a standardized therapeutic attitude in this type of pathology but has been associated with marked clinical improvement [6]. The prognosis for emphysematous cystitis is most often favorable, but may progress to emphysematous pyelonephritis with risk of septic shock. There is also a risk of necrosis of the bladder wall, which can lead to rupture with a prevalence of death of around 7\% [7].

\section{CONCLUSION}

The diagnosis of emphysematous cystitis is relatively easy and is based on the elements of the anamnesis and the various radiological examinations. The prognosis depends on the earliness of the antibiotic treatment as well as the emptying of the bladder and also on the control of the diabetic balance.

\section{REFERENCES}

[1] Egawa S, Utsunomiya T, Uchida T, et al. Emphysematous pyelonephritis, ureteritis, and cystitis in a diabetic patient. Urol Int 1994;52:176-8.

[2] Thomas AA, Lane BR, Thomas AZ, et al. Emphysematous cystitis:a review of 135 cases. BJU Int 2007; 100:17-20.

[3] Biogeau, M. Lamandé , H. Ripault , I. Léger , V. Dardaine-Giraud. Emphysematous cystitis: Report of one case. La Revue de médecine interne 39 (2018) 192-194

[4] Grupper M, Kravtsov A, Potasman I. Emphysematous cystitis: illustrative casereport and review of literature. Medicine 2007;86(1):47-53.

[5] A. Clémenc ot , A. Meyrieux, T. Schneider Emphysematous cystitis Journal Européen des Urgences et de Réanimation (2019) 31, 57-59.

[6] Arnaud Bracq, Marc Fourmarier, Olivier Bourgninaud, Frédéric Boutemy, Manuel Demailly, Jacques Petit, Fabien Saint. Cystite emphysémateuse compliquée de perforation vésicale : diagnostic et traitement d'une observation rare. Prog Urol, 2004, 14, 87-89

[7] Thomas AA, Lane BR, Thomas AZ, Remer EM, Campbell SC, Shoskes DA. Emphy-sematous cystitis: a review of 135 cases. BJU Int 2007;100:17-20. 